\section{Significados etnográficos no processo de licenciamento ambiental da usina hidrelétrica Corumbá IV: edificando padrões operacionais}

\section{Ethnographic meanings in the process of environmental licensing of the hydroelectric power plan Corumbá IV: building operational patterns}

\section{Resumo}

Este artigo tem por objetivo refletir acerca do processo de regulamentação ambiental da usina hidrelétrica Corumbá IV, no município de Luziânia, entorno de Brasília. O maior desafio está em compreender o processo de formação de significados presentes na interação entre atores envolvidos no pagamento de indenizações, além da regulamentação de normas ambientais, travando embates de territorialidades. Grosso modo, este trabalho atribui à situação social de construção da hidrelétrica as questões de representações, de atos rituais, de normas, de valores e de moralidades que compõem polissemicamente uma ordem de relações morais. A heterogeneidade dos atores envolvidos e a variedade de eventos compõem as complexas interações em torno da realidade da hidrelétrica, obrigando os atores a reordenarem e resignificarem suas posições e perspectivas, edificando uma nova ordem discursiva (talvez uma nova ordem moral). A perspectiva analítica deste artigo vincula-se a uma antropologia da burocracia.

Palavras-chave: Usina hidrelétrica Corumbá IV. Territorialidades. Espectro semântico. Moralidades. Antropologia da burocracia.

\begin{abstract}
The purpose of this paper is to analyze the changes brought within the installation of the hidroeletric power plant Corumbá IV, in Midwest of Brazil. It is observed that different modes of symbolizing the territory and its resources are in competition, notably, among peasant, governmental agencies, environmentalists and entrepreneurs. The hypothesis of this article is that the hydroelectric plant produces a semantic spectrum itself. Roughly speaking, this paper attributes to hydroelectric context values and morals that make a polysemic order from moral relations. The heterogeneity of the actors involved and the variety of events make up the complex interactions around the reality of the dam, forcing the actors to reorder their positions and prospects, building a new discursive order (perhaps a new semantic spectrum). The analytical perspective of this article is linked to the anthropology of bureaucracy.
\end{abstract}

Keywords: Hydroelectric power plant Corumbá IV. Territories. Semantic spectrum. Moralities. Anthropology of bureaucracy.
Doutor em Ciências Sociais pela Universidade de Brasília. 


\section{Introdução}

Este artigo tem por objetivo refletir acerca do processo de regulamentação ambiental da Usina Hidrelétrica (UHE) Corumbá IV, no município de Luziânia, entorno de Brasília. O maior desafio está em compreender a formação de significados presentes nas interações entre os atores envolvidos nas desapropriações de terras e no processo de regulamentação ambiental da hidrelétrica. Esses dois eixos analíticos comungam para refletirmos acerca das novas territorialidades produzidas desde os conflitos instalados pela hidrelétrica. As interações entre agências governamentais (servidores públicos), empreendedores (engenheiros empregados da Concessionária Corumbá S.A.) e atingidos (proprietários rurais, trabalhadores rurais, posseiros, roceiros que tiveram suas terras total ou parcialmente desapropriadas para a instalação da usina) impõem um jogo de negociações de significados que intervêm em práticas territoriais, em usos da terra e em mudanças normativas.

Ao longo da pesquisa de campo, observaram-se alguns padrões ${ }^{2}$. Primeiro, há três segmentos analisados, que se definem a partir de sua relação com a UHE:

a) aqueles que tiveram suas terras parcial ou totalmente desapropriadas para a instalação do reservatório da usina hidrelétrica;

b) a diretoria, os empregados, os engenheiros e os acionistas da concessionária de serviço público Corumbá Concessões S.A., que são interpretados como operadores dos interesses da hidrelétrica ${ }^{3}$; e

c) o Instituto Brasileiro do Meio Ambiente e dos Recursos Naturais Renováveis (IBAMA) e a Procuradoria Geral da República (PGR), analisados como atores estatais que possuem missões específicas, muitas vezes, associados em prol de diminuir as assimetrias entre os dois atores anterior-

2 É importante esclarecer que o trabalho de campo a partir do qual essas reflexões foram realizadas se efetivou em 2006 e 2007, durante minha dissertação de mestrado (MEDEIROS, 2007) e durante consultoria a pedido do Ministério Público e financiado pelo empreendedor em que se envolveram doze pesquisadores. Dessa consultoria saíram duas dissertações de mestrado: Medeiros (2007) e Assis (2007).

3 Concessão: decisão administrativa que dá o direito de explorar ou utilizar um bem público. Essa decisão depende da vontade das autoridades que fixam unilateralmente as condições (Terminologia Energética; Edição da Comissão Nacional Portuguesa da Conferência Mundial da Energia, 1986). mente mencionados, para tanto, cada um se utiliza de suas práticas, da legislação ambientalista, das garantias e direitos individuais para promover uma maior legalidade ${ }^{4}$ do empreendimento.

Esses aglomerados de indivíduos e instituições (formais e informais) se configuram, neste artigo, como sujeitos cognitivos de ações e de moralidades relacionados ao contexto da hidrelétrica. É nesse sentido que podemos conjecturar alguns padrões morais nessas redes. Apesar disso, identificamos inúmeras tensões não só entre os grupos de atores mencionados, mas também dentro deles observamos tensões entre dar legitimidade à obra (garantir sua operacionalidade) versus inviabilizar sua instalação/operacionalidade.

Essas tensões, em princípio, operam mudanças normativas com relação ao uso da terra trazidas com a instalação da hidrelétrica. Podemos caracterizar essa situação como um jogo assimétrico em que o local de fala das agências reguladoras e do empreendedor é dominante, mas não é absoluto. Descrever as interações de imposição (e/ou negociação) de regras ambientais que procuram estabelecer mudanças na perspectiva de ocupação territorial, dentro do contexto de construção (instalação e operação) da hidrelétrica, permitenos analisar as relações entre o que estou denominado de moralidades. Moralidades são modos de simbolizar o território e seus recursos dentro de dinâmicas coletivas próprias (DURKHEIM, [1906] 1970). Este trabalho atribui à situação social de construção da hidrelétrica as questões de representações de atos rituais, de normas e de valores que compõem polissemicamente uma ordem de relações morais entre os diversos grupos sociais que

\footnotetext{
${ }_{4}$ Legalidade se diferencia de legitimidade e de reconhecimento, como demonstram Roberto Cardoso de Oliveira e Luís R. Cardoso de Oliveira (1996).
} 
compartilham os dramas e as liminaridades da instalação da hidrelétrica (TURNER, 1974) ${ }^{5}$.

Grosso modo, os três segmentos analisados produzem (e são produto) de três moralidades distintas que entram em concorrência no contexto da UHE Corumbá IV: a camponesa/sertaneja (SUÁREZ, 1982; WOORTMANN, 1990), a normativista para a regulamentação ambiental (agências estatais) e, por fim, a empreendedora/desenvolvimentista (Concessionária). De um lado, temos concepções normativistas em que o empreendedor deve cumprir procedimentos (condicionantes) e legislação ambiental para viabilizar seu empreendimento, sendo fiscalizado por servidores públicos federais do IBAMA e da PGR. De outro lado, temos a diretoria da UHE, que procura minimizar custos operacionais, manter o cronograma do empreendimento e garantir a lucratividade dos acionistas, dimensionando custos legais e operacionais. Por sua vez, temos proprietários, posseiros e trabalhadores rurais que são desapropriados e prejudicados em suas atividades, insatisfeitos com as mudanças provocadas

\footnotetext{
${ }^{5}$ De acordo com Kuper, a análise situacional de Gluckman em que ele descreve pormenorizadamente uma única situação social na Zululândia indica o "descontentamento com os modos convencionais de apresentação do material etnográfico ilustrativo. Representou uma reação contra a seletividade da técnica malinowskiana de 'ilustração apta' (...) os seus experimentos frutificaram no uso por Tuner dos 'dramas sociais, mais tarde denominados 'extended-case studies', uma técnica particularmente adequada ao estudo dos processos de conflito e resolução de conflito" (KUPER, 1978, p. 177).
}

pelo empreendimento, tendo que adaptar sua vida produtiva à nova ordem territorial ${ }^{6}$.

\subsection{Desafios empíricos e analíticos}

Numa dimensão mais específica, este artigo versa sobre as relações entre os atores e agências envolvidos no contexto de instalação e operação da UHE Corumbá $\mathrm{IV}^{7}$, tendo como foco de discussão a formação de moralidades. Ao descrever e analisar dinâmicas de mudanças provocadas (e negociadas) no contexto de construção (instalação e operação) da usina hidrelétrica, o artigo procura definir os modos de simbolizar o território que entram

6 Em algumas falas o termo prejudicado aparece mais do que atingido ou impactado, termos que são muito utilizados na literatura específica de situações de hidrelétricas. No caso aqui analisado, o termo prejudicado se apresenta da seguinte maneira:

"Nós aqui fomos muito prejudicado com essa barragem. Ninguém tem mais um roçado boa para tocar. Esta Corumbá foi uma tentação que apareceu, desestabilizou tudo, inquietou o povo da região tudo. Só prejudicou" (Morador da Comunidade Barreiro da Boa Vista, Abadiânia, ao se referir ao seu desgosto por ter que vender parte de suas terras para a Corumbá Concessões S.A).

"O cantinho [de terra] de melhor valor foi o que eles pegaram porque era na beira da água, então, deviam, pelo menos, indenizar um troco melhor para construir um barraco melhor porque ficamos sem a terra, sem as plantaçõezinhas que tinha no quintal, porque no caso de sair perde tudo. Aqui dá para desfrutar, mas se for preciso sair, eles podem vir uma noite e tirar tudo qualquer hora. Ficou muita gente prejudicada com isso porque fizeram de qualquer jeito e quem chegar para conversar e falar que tem de ser assim, desse jeito e pronto. Podia pagar uma coisa melhor e eles falavam que não, que se não aceitássemos tínhamos de ir para a lei. Muita pressão! Instruir as pessoas que não tinham experiência para negociar e acabaram sendo prejudicados" (Morador da Fazenda Pinguela, Santo Antônio do Descoberto, ao se referir à negociação para indenização com os representantes da Corumbá Concessões S.A.).

A população que foi desapropriada para a instalação da usina relaciona o processo de negociação de suas terras e benfeitorias com o termo prejudicado. São raras as referências a atingido ou impactado. É mais comum utilizar prejudicado para expressar sua condição com relação às mudanças promovidas pelo UHE.

7 A instalação e a operação são convenções que delimitam dois momentos das hidrelétricas. O momento de instalação é o período de construção que se exigem o EIA-RIMA (Estudo de Impacto Ambiental e Relatório de Impacto Ambiental), a liberação da Licença Prévia de Instalação, os estudos técnicos para a Licença de Instalação. Com a licença de instalação, os órgãos reguladores e licenciadores autorizam a construção da usina. A operação é o momento de funcionamento da usina em que ela produz energia. Essa fase de operação demanda a Licença de Operação que é expedida pelo órgão licenciador (IBAMA ou agências ambientais estaduais). 
em concorrência, notadamente, moralidade camponesa, concepções ambientalistas e perspectivas desenvolvimentistas.

Os principais desafios enfrentados por este artigo são de duas ordens:

a) Empírico - descrever eventos e narrativas mais emblemáticos que representem atuações, associações, relações e cooperações entre os agentes formuladores das novas realidades territoriais da região e

b) Analítico - formular análise crítica que dê conta da complexidade e da heterogeneidade dos processos nos quais os atores sociais estejam envolvidos.

Para enfrentar esses desafios, o artigo percorre discussões clássicas e contemporâneas para formular uma abordagem teórico-metodológica que consiga criar caminhos específicos para compreender as particularidades deste recorte empírico-analítico. Essas duas dimensões do trabalho não são, a priori, separadas. A separação se faz necessária para viabilizar a análise e a apresentação do texto. Contudo, o desafio último é formular uma interpretação que integre essas duas dimensões.

Das inúmeras abordagens possíveis para tratar a realidade em foco, optou-se por descrever, ordenar e analisar a complexidade interacional por meio de uma abordagem que vincule os eventos, a situação de construção da hidrelétrica e as redes a uma dimensão moral sui generis que constrói significados particulares sobre os sujeitos, os agrupamentos-redes e as perspectivas implicadas. Em suma, o desafio empírico está exposto no exercício de descrever a complexidade das agências e dos atores e suas interações dentro de eventos delimitados teoricamente pelo pesquisador. E, por sua vez, o desafio analítico não se limita ao caminho teórico-metodológico percorrido para construir as conclusões deste trabalho, mas, constitui também condição para que as explicações dos eventos e dos significados reunidos num texto etnográfico se tornem inteligíveis para os leitores.

É neste sentido que tanto o desafio empírico quanto o analítico são partes de um mesmo processo, separáveis apenas para efeito de apresentação, mas que, de fato, compõem um único desafio que é o de compreender uma realidade socionatural em mudança. Assim, as perguntas que orientam este trabalho buscam articular as dimensões empíricas e teóricas, a saber:

a) Como atuam os atores envolvidos no contexto da Usina Hidrelétrica Corumbá IV?

b) Quais são suas ações vinculadas à hidrelétrica?

c) De que modo esses agentes se vinculam e se relacionam em ação?

d) As interações no contexto da hidrelétrica podem produzir um campo semântico próprio?

\subsection{A formalidade dos números}

O reservatório da Usina Hidrelétrica Corumbá IV inundou áreas de sete municípios goianos e pequena parte do Novo Gama, no Distrito Federal. Os municípios goianos que tiveram áreas inundadas foram: Abadiânia, Alexânia, Corumbá de Goiás, Gameleira de Goiás, Luziânia, Santo Antônio do Descoberto e Silvânia. O reservatório ocupa uma área de $173,3 \mathrm{~km}^{2}$ que desapropriou parcial ou totalmente 634 propriedades em um total de 27,5 mil hectares de terras adquiridos pela concessionária ${ }^{8}$. $\mathrm{O}$ reservatório de uso múltiplo (geração de energia e abastecimento) funciona em regime de deplecionamento entre cotas (mínima de 837 metros e máxima de 842 metros), o que cria, em algumas localidades, grandes variações nas áreas inundadas durante os ciclos de chuvas e de seca característicos do cerrado. Essa variação tem implicações produtivas para os locais, impacta na regulamentação ambiental e no gerenciamento do lago, envolvendo os três atores em um contexto de permanente interação para solução de conflitos. Esses dados dão uma ideia geral acerca da dimensão do impacto humano, territorial e ambiental do empreendimento.

\section{A moralidade do prejudicado: sertanejo}

Posseiros, proprietários escriturados e comunidades, que foram desapropriados para a instalação do

8 Há divergências sobre esses números. Desse total de 634 propriedades, tive conhecimento documental de todas, no entanto, tive contato face a face com aproximadamente 200 propriedades. As propriedades foram classificadas por critérios que surgiram ao longo do licenciamento, a saber: propriedades reduzidas a menos de um módulo rural, situação de espólio e o residente produtivo, alterações provocadas na/pela malha viária, construções e benfeitorias presentes na Área de Preservação Permanente, remanejados e realocados. 
empreendimento, apesar do recebimento de indenização da terra e das benfeitorias, não se sentem contemplados nos processos de negociações. A monetarização da vida não os contempla. Há um caso emblemático que acompanhei durante minhas primeiras visitas à região de Corumbá IV. Em conversa com um proprietário rural desapropriado sobre sua condição e sobre a negociação das terras inundadas, uma das primeiras frases que verbalizou sobre as negociações foi "não me pagaram o que valiam meus pés de jabuticaba”. Fiquei processando essa questão por um tempo: quanto vale uma jabuticabeira? Procurei o agrônomo responsável pelas negociações e li o laudo técnico que estipula o valor monetário da jabuticabeira. A técnica naturaliza a perspectiva monetarizante da vida. Constatei que a metodologia de estipular o valor monetário dos "bens" desapropriados por meio de taxas de depreciações e de fórmulas para calcular o lucro cessante levam em consideração quanto os "bens" poderiam produzir de lucro para os proprietários num determinado período de vida útil das "coisas". Contudo, nada consta sobre a dimensão simbólica. Talvez nem pudesse constar, porque quanto vale um quintal cheio de jabuticabeiras, mangueiras, goiabeiras e criações que fazem parte da trajetória (VELHO, 1994) produtiva de uma família? Talvez não seja monetarizável.

Para a maioria dos desapropriados, o que está em jogo não é apenas a dimensão monetária de quanto custa a terra e as benfeitorias. Há algo para além do pragmático quantitativo dos métodos contábeis de mensuração de "bens". As técnicas servem para conferir neutralidade e dar alguma legitimidade jurídica para o procedimento de indenização. Porém, a "neutralidade" jurídica é percebida como insensibilidade pelos moradores. Inclusive, o IBAMA e a PGR contestaram os termos negociais da Corumbá, alegando que não houve padronização no critério de desapropriação e pagamento de indenizações. A Corumbá Concessões S.A. se defende via laudos técnicos que garantem sua legitimidade processual. No meio desse jogo, ainda fica sem resposta a pergunta do desapropriado que reconhece que recebeu um valor em reais por cada jabuticabeira de seu quintal, mas que ainda alega: "não pagaram a jabuticabeira”. Os desapropriados, de modo geral, sabem que a dimensão simbólica não é objeto da indenização e procuram fazer acordos pragmáticos sobre o que consideram que suas terras valem enquanto potencial para produção, mas, mesmo assim, quando perguntados, expressam suas perspectivas sobre o valor simbólico das coisas, de modo também bastante pragmático: "Nem a terra ele não paga direito quem dirá ressentimento. Eu falei para ele. Eu não gosto nem de lembrar. Tenho depressão" (morador de Alvoradinha, Município de Alexânia).

Há bastante ruído na interação entre o empreendedor e os proprietários rurais. É possível acessar as mudanças, as rupturas e as transformações na dimensão moral e simbólica? Se considerarmos as narrativas discursivas como a expressão de um conjunto de valores ou de uma ideologia, que possuem suas implicações práticas, perceberemos que os enunciados referentes à terra, ao valor das "coisas", ao ressentimento, ao desgosto por ter visto a terra inundada. Possuem uma comensurabilidade com os discursos e a perspectiva advindos do empreendedor e dos órgãos públicos. Busco justamente essa comensurabilidade que estabelece vínculos e troca de categorias, perspectivas e conceitos dos moradores locais (camponeses) após a experiência da interação.

No plano discursivo, em que o concreto se apresenta nos valores e nas ideias enunciadas nas diferentes conceituações, procuro analisar a dinâmica de (re)formulação de significados que ordenam as ações dos atores envolvidos nos diversos contextos rituais propiciados pela situação-evento Corumbá IV, estabelecendo mudanças em suas trajetórias e perspectivas. Portanto, por trás dessa caracterização moral do que é ser um "roceiro" ou um "trabalhador rural", a marca da identidade social é a legitimidade da posse da terra por uma classe que se considera capaz de produzir por causa das suas qualidades morais e do seu saber tradicional. A compra de terras por pessoas "de fora" do meio rural aparece como ameaça diante da situação fundiária local, porque faz com que se tenha menos terra para cultivar. Outros dois elementos do discurso também são muito fortes para a afirmação de uma identidade de "produtor rural": a autossuficiência na produção de alimento para consumo (policultura, diversidade na produção) e a lida (trabalho ou luta para sobreviver da terra). Assim como Woortmann (1990) considera que, para alcançar um modelo de campesinidade, é necessário passar de uma ordem econômica para uma ordem moral; no contexto de conflito da Usina Hidrelétrica Corumbá IV, sugerimos que é necessário vislumbrar a passagem de uma ordem moral para uma ordem política para que possamos pensar na mediação de categorias, 
conceitos e percepções sobre o território, as negociações e as mudanças.

\section{A moralidade do empreendedor}

Será possível apreender do evento-situacional Corumbá IV uma noção do que poderia ser uma ordem moral desenvolvimentista? Não creio que tamanha ambição seja viável neste trabalho. Para ter uma ideia da moralidade empreendedora dos diretores, engenheiros e acionistas que compõem a Corumbá Concessões S.A., centrarei a análise numa entrevista com o presidente-diretor que gerenciou a concessionária durante a maior parte do tempo em que ocorreram as negociações para pagamento de indenizações.

Em 2003, o engenheiro civil Faustino Márquez foi convidado pela empresa construtora que detinha mais ações no consórcio para assumir a presidência do empreendimento. "Doutor Faustino", como é chamado por seus pares, já possuía ampla experiência na área de construção civil, principalmente naquilo que ele chama de obras pioneiras para o desenvolvimento:

"Esse tipo de trabalho que eu faço. Obras pesadas, seja hidrelétrica ou abertura de estradas, elas são obras pioneiras que requerem um grande planejamento, uma forte logística. São empresas de grande porte que permitem essas grandes obras. Fazer uma obra dessas em um lugar no meio do nada como Tucuruí, que só se pode chegar a barco, requer realmente uma grande logística. É de grande satisfação fazer esses tipos de obra. É uma satisfação você fazer nascer no nada algo que vai trazer benefícios para muitas pessoas. Hoje, muito diferente do passado, dá-se muita importância à área ambiental. Em qualquer empreendimento desse, você sempre vai trazer impactos ambientais. Uma hidrelétrica vai desalojar pessoas. O benefício vem depois. Isso é difícil de se evitar. Agora, um planejamento ambiental bem feito minimiza esses problemas. Então, a Corumbá pra mim foi a primeira obra que eu fiz.... No caso da Corumbá, era um pouco diferente: eu era o dono da casa, eu contava como os pedreiros para fazer o trabalho. A satisfação disso é ver a obra concluída. Eu faço obras que, quando eu passo com os meus filhos em Campinas, Salvador, elas ainda estão lá e, quando eu sair daqui, elas não vão deixar de existir. Elas vão continuar aí". (Faustino Marques, em entrevista concedida no dia 27/11/2006, no escritório da Corumbá Concessões S.A. em Brasília).

O primeiro destaque que considero importante fazer para entendermos a perspectiva desenvolvimentista dos empreendedores da Corumbá pode se identificar na frase: "fazer uma obra dessas em um lugar no meio do nada". Essa sentença representa um pouco do que é considerado "algo importante" ou "como deve ser o mundo" (ou o território a ser modificado). O lugar que não está integrado no grande sistema de produção é lugar nenhum, ou seja, um "nãolugar". Para ter significado, uma localidade precisa produzir em termos de escala industrial e estar integrada a um sistema de produção macro. Isto é, o rio sem usina hidrelétrica não significa nada, um território sem construção que gere "riqueza" (ou mais-valia para os detentores do capital) é um "não-lugar". Esses lugares ermos só começam a fazer sentido para os empreendedores quando se inicia a construção de algo "realmente importante para o progresso".

A retórica tenta transparecer que o empreendimento é para beneficiar todos, mesmo que alguns tenham que se sacrificar para o "bem comum". Está muito presente a ideia de que sacrifícios precisam ser feitos por uma minoria (os empreendedores se incluem nessa minoria), para que a grande maioria se beneficie com o progresso:

"A Corumbá é um caso excepcional, melhor que as demais. Corumbá alagou um pouco de terras férteis, nas margens do rio, mas a região construída por Corumbá é uma região ruim onde a qualidade de terra seja pra agricultura seja... a não ser alguns campos que são utilizados para o cultivo de soja e uma pequena faixa na beira do rio que tinha influência das cheias e, por isso, que a terra é um pouco melhor. No geral, é uma terra, eu não diria ruim, mas não é a melhor terra do Goiás. Essa é a desvantagem, qual é a grande vantagem? Corumbá, com os seus 17.400 ha inundados na região, propiciou uma melhora relativa na qualidade do meio ambiente, como a umidade relativa do ar. Saindo daqui para Goiânia, você percebe uma neblina densa na estrada. Isso melhora muito as propriedades do ar, das regiões vizinhas... numa região como o Centro-Oeste, que é muito seca nessa época. Sem contar a grande área de lazer que a Corumbá propicia. Só tem que ser muito bem administrada para não deixar que isso se deteriore através de uma ocupação desordenada. Mas é muito bom. Para que você tenha uma ideia, hoje um ha de terra que estava na faixa de 5 mil reais, hoje você encontra por 50 ou $60 \mathrm{mil}$, dez, doze vezes mais o valor inicial. Então os proprietários próximos dali estão com a terra totalmente valorizada. Quem pode se sentir prejudicado ali são aqueles que tiveram sua terra totalmente inundada e que foi indenizada pelo valor que sua terra possuía naquele momento. Isso só vale hoje por conta do lago. As terras no Brasil inteiro estão abaixando o preço em função da crise da agropecuária. Um dos poucos lugares que eu não vi abaixar foi a Corumbá" (Faustino Marques, em entrevista concedida no dia 27/11/2006, no escritório da Corumbá Concessões S.A. em Brasília). 
A valorização monetária das terras, os benefícios de aumento de turismo, o incremento na economia local são considerados pelos empreendedores da Corumbá como benefícios incontestáveis da hidrelétrica para a região. Esses valores estão diretamente em contraste com a ordem moral camponesa, segundo a qual a terra tem um significado produtivo familiar e de trabalho. De certa forma, quando questionado sobre as mudanças profundas na produtividade das famílias locais, o ex-presidente reconhece que o progresso traz "alguns poucos elementos negativos", mas é um "mal necessário":

\begin{abstract}
"Construir para mim é mais ou menos o seguinte: construir, desenvolver, abrir fronteiras agrícolas. É sempre uma necessidade enquanto a população estiver crescendo. Toda vez que nasce uma pessoa, essa pessoa vai precisar de energia, alimentação, vestuário, vai precisar de um carro, vai consumir algum tipo de combustível. Isso não tem como evitar. A única forma é você impedir que nasçam pessoas. Se nasce pessoas, elas vão demandar por isso. Existe um limite que você pode demandar do já existente". (Faustino Marques, em entrevista concedida no dia 27/11/2006, no escritório da Corumbá Concessões S.A. em Brasília).
\end{abstract}

O que está em evidência numa possível moralidade desenvolvimentista é o ímpeto do valor de progresso que perpassa todas as ações e argumentos dos atores da Corumbá Concessões. Portanto, a degradação do outro para viabilizar a existência de quem o domina e subjuga no evento-situacional Corumbá IV é defendida em nome de conceitos sem maiores comprometimentos políticos, tais como "bem estar de todos", "tecnologia", "progresso". Em princípio, ninguém seria contra essas palavras que designam noções positivas, contudo, a operacionalidade das palavras é a regra do jogo que fica escondida. Portanto, só quando as cortinas se fecham é que os termos "desvalidos", "pobres coitados" aparecem para dar a dimensão pejorativa e preconceituosa das perspectivas desenvolvimentistas. Resta saber para quem a UHE Corumbá IV “é uma dádiva"? Como querem se fazer acreditar os diretores, engenheiros e acionistas da Concessionária?

\section{A moralidade da normatização ambiental: IBAMA e PGR}

Precisamos nos perguntar de que maneira definições particulares de natureza servem a interesses particulares, sejam esses o lobby preservacionista, os estudos técnico-científicos que embasam a viabilidade de obra de infraestrutura ou a estratégia de povos indígenas que veem vantagens em reinventar uma tradição particular de natureza (FOLADORI; TAKS, 2004, p. 327).

No contexto das disputas por conceitos e recursos em que o Estado situa seu entendimento do que é "certo" e "errado" nas ações de desenvolvimento e preservação/ conservação, a normatividade do Estado brasileiro, para lidar com os desafios socioambientais, encontra-se cada vez menos emancipatória de grupos historicamente marginalizados. Focarei especificamente na questão das Áreas de Preservação Permanente (APPs).

A APP é um artefato técnico que busca inscrever nas realidades modificadas pelas hidrelétricas uma compensação ambiental e um "cinturão protetor" para o reservatório (nos termos de um servidor do IBAMA responsável em monitorar as condicionantes da Corumbá Concessões S.A.). A resolução nº. 302/2002 do CONAMA que regulamenta a APP em torno de reservatórios artificiais define a APP como:

A área marginal ao redor do reservatório artificial e suas ilhas, com a função ambiental de preservar os recursos hídricos, a paisagem, a estabilidade geológica, a biodiversidade, o fluxo gênico de fauna e flora, proteger o solo e assegurar o bem-estar das populações humanas (CONAMA, Resolução 302/02).

Para o reservatório artificial da UHE Corumbá IV, a legislação estabelece faixas marginais com, no mínimo, 100 metros no entorno do reservatório. A lei 8.171 de 1991, que trata, dentre outras coisas, das competências institucionais e estabelece as ações relativas às atividades agropecuárias, agroindustriais e de planejamento das atividades pesqueira e florestal, em seu Artigo 23 afirma que:

As empresas que exploram economicamente águas represadas e as concessionárias de energia elétrica serão responsáveis pelas alterações ambientais por elas provocadas e obrigadas à recuperação do meio ambiente, na área de abrangência de suas respectivas bacias hidrográficas. (BRASIL, Lei 8.171 de 1991).

A área onde hoje é a APP de 100 metros, às margens da UHE Corumbá IV, antes constituía parte das propriedades e posses rurais que ali se encontravam. Por isso, a utilização desse espaço destinava-se à plantação de pomares, campineiras e outras culturas anuais, centrais para a produtividade da maioria das propriedades. Mesmo com as recomendações de uso da APP feitas pela Corumbá Concessões S.A. (com base nas orientações do 
IBAMA), segundo as quais não seria permitido arar a terra, abrir novas áreas de plantio nem roçar a regeneração nativa no pasto, a área ainda representa um espaço de disputas conceituais e de categorizações divergentes sobre como se devem utilizar as terras, quais os direitos dos proprietários que celebraram no momento do pagamento das indenizações o contrato de Cessão de Uso que daria ao proprietário, posseiro e arrendatário permissão para usufruir a terra no período de 35 anos (período da concessão que é renovável por igual período).

O IBAMA exigiu que o contrato de Cessão de Uso fosse cancelado porque entendia que esse contrato iria inviabilizar o reflorestamento da APP. Essa situação é interessante para observarmos as interações entre as agências e estabelecermos suas perspectivas e moralidades. É nesses termos que a maior parte do material etnográfico analisado e apresentado neste trabalho faz sentido no contexto das interações entre os atores sociais. Essas interações entre proprietários desapropriados e empregados da concessionária Corumbá IV versam sobre: a negociação dos valores das indenizações, os contratos de Cessão de Uso das APPs, termos legais de desapropriação que implicavam a desapropriação por utilidade pública, na máxima "hidrelétrica para o bem de todos".

\begin{abstract}
"Por um lado trouxe benefício, por outro prejuízo. Benefício - vai trazer água e energia para Brasília. E prejuízo porque muitas áreas eram produtivas e que hoje tem muitas pessoas que estão sem moradia. Porque desapropriou e o que sobrou não presta para tocar lavoura e eles não acertaram com ninguém" (Resposta de proprietário da localidade São Roque, Município de Silvânia, quando perguntado sobre o que achava da Corumbá IV).
\end{abstract}

As moralidades que orientam o desempenho ou o cálculo político dos atores para seus respectivos agrupamentos tornam visíveis as redes de relações que para eles são significativas. À medida que as pessoas desapropriadas começam a se apropriar das concepções acerca da APP como "terra do governo" ou como "terra da Corumbá que não tem dono" e fazem uma leitura própria desde uma lógica produtiva camponesa, esses artefatos técnico-burocráticos em que a noção de Área de Preservação Permanente está pautada começam a ter outra dimensão significativa. É esse ponto que considero como a constituição de uma terceira ordem moral se forma na interação entre os atores sociais:

"Essa terra aí da Corumbá é terra sem dono [...] quando nós dizemos que pros pescadores que não pode acabar com os matos e que tem que manter a área formada, eles falam que estão na terra do governo, [porque] estão na reserva [APP] ..." (Proprietário de terra no Assentamento do INCRA Barro Amarelo, Abadiânia, ao se referir à Área de Preservação Permanente e aos problemas com os pescadores).

Do mesmo modo, do lado das instituições regulamentadoras, tais como o IBAMA, há a aproximação de termos em que o concreto se apresenta nos valores e nas ideias enunciadas nas diferentes conceituações. A análise do caso UHE Corumbá IV nos faz refletir sobre alguns aspectos do processo de licenciamento: dentro do jogo político que se insere numa comunidade de argumentação, as pessoas locais são vistas como parte integrante do meio ambiente tanto pelo discurso ambientalista das agências estatais quanto pelo discurso desenvolvimentista da concessionária. Como analisa Carlos Vainer (2001), no processo ambiental (instrumento do licenciamento) é que a lógica ambientalista impõe seus conceitos e definições da realidade ${ }^{9}$. Do mesmo modo, os empreendedores o fazem para emplacar suas obras. É nesse momento que as pessoas que possuem terras desapropriadas são mais uma vez desapropriadas, agora em um sentido de definições de como utilizar a terra que ainda resta (ou do novo ordenamento territorial, como querem as agências estatais). Sem mecanismos que permitam impor suas concepções sobre a realidade, os que tiveram seus trabalhos e suas terras desapropriadas não conseguem modificar o destino traçado para as APPs que estejam em suas propriedades. Essa constatação me leva a crer que as interações locais assumem um papel central para contestar os modelos fechados do licenciamento. É no momento do acordo para desapropriação ou para formação da APP ou ainda para tratar de "reparos" na malha viária ou para tratar de outro tipo de mitigação que as moralidades locais deveriam aparecer com força no intuito de opinar sobre os destinos do ordenamento territorial. É importante ressaltar que as mudanças na perspectiva dos agrupamentos locais são produzidas não somente em função do empreendimento em si, mas também de seus desdobramentos políticos-burocráticos que possuem diferentes formas de conceber a gestão do território.

"Aqui cobriu quase tudo. O que não cobriu é reserva. Essa casa está dentro da reserva. Falaram

\footnotetext{
9 Ver também Santos (1988), Baines (1994), Catullo (1996), Vianna (1996).
} 
que ia ter 35 anos para morar no combinamento. Depois não pode mais. Ficaram poucas famílias onde sobrou terra" (Proprietário de terra na localidade Monjolo, Alexânia, ao se referir às negociações com a Corumbá Concessões S.A.)

"Na negociação ficou combinado que minha casa e minhas benfeitorias [Contrato Verbal de Cessão de Uso ${ }^{10}$ para casa na $\mathrm{APP}$ ] podiam ficar, não quiseram desmanchar e não pagaram. Agora, se tiver que sair, vai ser preciso um novo combinado, porque não sobrou nada. Antes da barragem eu tinha 6,6 hectares. A inundação e a APP tomaram 5,8 hectares. Sobrou nada. Está tudo na área de preservação" (Proprietário na localidade Pinguela sobre a condição de sua terra que se encontra totalmente na área de preservação ambiental, município de Santo Antônio do Descoberto - com adaptações)

"A terra de baixada que era boa para roçado, agora não pode mais mexer" (Proprietário de terra na localidade Cutia, município de Corumbá de Goiás).

Geralmente, o que ocorre são alterações ambientais, culturais e sociais que quebram dinâmicas anteriormente existentes, modificando a sobrevivência e a reprodução social das populações locais. Observa-se que alguns pequenos produtores tiveram sua produção comprometida, simultaneamente, por causa da inundação das “terras de baixada” - na concepção local, as mais fortes para o plantio e para pastagem da tropa (gado e cavalo) e por causa da figura da Área de Preservação Permanente (APP), que limita o uso da terra e reduz significativamente a possibilidade de alguns proprietários permanecerem exercendo suas atividades produtivas. As mudanças e rupturas consistem nas imposições objetivas sobre o território, isto é, nas novas formas de se conceber esse território. Entretanto, os instrumentos legais do licenciamento regulamentam novas obrigações legais vinculadas à gestão dos territórios ocupados pelos proprietários que continuam na terra, o que implica modificações tão ou mais significativas.

O que está em jogo são concepções de territorialidades distintas e que, em alguma instância, disputam espaço, poder e domínio sobre os recursos naturais. As duas perspectivas podem ser aglutinadas nas seguintes

10 Contratos de Cessão de Uso para utilização de casa e outras construções na Área de Preservação Permanente foram pactuados por igual período ao da Concessão, seja na forma de acordos assinados ou verbais. Esses acordos entre a concessionária e os desapropriados não foram reconhecidos pelo IBAMA por ferirem o princípio das APPs. classificações: território como recurso e território como morada-produção. Edna Castro (1997, p. 166-167) define território como:

[...] o espaço ao qual um grupo garante aos seus membros direitos estáveis de acesso, de uso e controle dos recursos e sua disponibilidade no tempo. Mas todas as atividades produtivas contêm e combinam formas materiais e simbólicas com as quais os grupos humanos agem sobre o território. $\mathrm{O}$ trabalho que recria continuamente essas relações reúne aspectos visíveis e invisíveis, daí porque está longe de ser uma realidade simplesmente econômica.

Grosso modo, cabe notar que não se trata de uma territorialidade substancializada ou colada nas práticas apenas cotidianas, mas de uma territorialidade relacional articulada à e pela maneira de ordenar e ocupar a "terra". A experiência territorial presente nas interações entre os agentes-atores remete a uma apropriação política do espaço, vinculada à administração, delimitação, classificação, habitação, uso e identificação das opções de ordenamento territorial. O território, por sua vez, apresenta-se como o resultado da territorialidade, que seria o esforço coletivo de um grupo para habitar, dominar, usar, e assim se identificar com o meio que ocupa (BARRETO, 1997).

Podemos perceber uma dicotomia na percepção da terra como recurso material, presente nas concepções desenvolvimentista e ambientalista, em contraste com a percepção de terra como morada dos denominados camponeses. Essa dicotomia se fundamenta em duas representações antagônicas da relação com a terra: em um caso, como uma relação de troca, na qual o homem ajusta suas necessidades à natureza da terra e, no outro caso, como uma relação utilitarista em que a terra é percebida como mercadoria, implicando que a natureza deva ser "corrigida" para promover o lucro (WOORTMANN, 1990). Na perspectiva do território como recurso, os instrumentos administrativo-burocráticos, em geral, objetivam imprimir uma lógica de ocupação que visa conservar e/ou preservar a qualidade da água, a sobrevivência da fauna e da flora, o uso ambientalmente adequado dos recursos naturais por parte da população local e que definem diretrizes para o ordenamento territorial com vistas a coibir a ocupação desordenada. Essas definições utilizadas pelos empreendedores (privados e/ou estatais) trazem um viés ambientalista e desenvolvimentista sobre o uso do território. 
Na perspectiva da terra como morada, o território configura, em algumas instâncias, a estrutura, a organização e a dinâmica das relações locais, sobretudo no caso dos produtores rurais das diversas localidades e municipalidades que compõem o reservatório. A transformação do espaço - como categoria do entendimento kantiana ou platônica - em território é um fenômeno de representação por meio do qual os grupos humanos constroem sua relação com a materialidade, num ponto em que a natureza e a cultura se fundem. Nesse sentido, a territorialidade deixa de ser substancializada e passa a ser relacional, ou seja, a territorialidade começa a ser resignificada em interações assimétricas entre velhos e novos atores para a localidade. De um modo eminentemente dialético, as interações constroem uma territorialidade desde o conjunto de perspectivas, legislações, estudos técnicos, reformulação das concepções locais para incorporar as mudanças, tais como as restrições impostas na utilização das APPs para atividades produtivas dos moradores. Desse modo, o território passa a ser ordenado por meio do conjunto de relações estabelecidas na situação do licenciamento ambiental (MEDEIROS, 2007).

\section{Convergência de moralidades: uma conclu- são possível}

As comunidades, fazendas, propriedades e territórios - que precisaram se reinventar devido à instalação da hidrelétrica - constroem algo para além da simples reorganização interna dos grupos. Há a edificação de uma nova semântica que reorienta o espaço e as relações. A formação espacial se torna importante quando toma o caráter de território, sendo, assim, produto de simbolizações que, diacronicamente, consolidam as relações de vizinhança, associativismo, sistemas de dádivas, relações comerciais e de trabalho, relações de parentesco e de amizade, novas configurações políticas e regulatórias com impacto nas políticas municipais. O desmatamento, a inundação das terras mais férteis, a regulamentação das APPs e o processo de loteamento de terras na margem do lago dão a dimensão das novas configurações políticas que envolvem prefeitos, secretários municipais, vereadores e lideranças comunitárias. São sobre essas novas configurações que recai o novo ordenamento territorial. O Comitê de Gestão da Bacia do Corumbá é um exemplo dessa nova configuração da política local.
Os processos de modificação, ruptura e transformação do território, tanto pela inundação quanto pela imposição de novas regras ambientais, exigência de registro da terra e uma lógica de exploração dos recursos naturais intensificam as diferenças entre os atores sociais, exigindo intensas negociações semânticas. De um lado há proprietários, posseiros, roceiros, trabalhadores rurais com seus modos tradicionais de lidar com a terra, de outro lado encontram-se empreendedores com sua perspectiva desenvolvimentista de simbolizar recursos naturais monetariamente e no meio das disputas, e, por fim, existem agências governamentais que procuram normatizar (tornar normal e regulamentado) as relações humanas e naturais. Melhor do que especular sobre as falas é pontuar alguns posicionamentos morais:

"Esse lago aí não tem valor para mim. Para mim
é tudo asfalto, não tem vida". (Depoimento de
um dos patriarcas de uma das quatro famílias
tradicionais da comunidade de Barreiro da Boa
Vista, município de Abadiânia, ao se referir ao
reservatório da UHE Corumbá IV que inundou
parcialmente suas terras).
"O sossego acabou. Fim de semana essas estra-
das se enchem de carros, é um perigo (...) Os
pescadores invadem as propriedade, fazem fo-
gueiras, acabam com o restinho da lenha que
ainda tem. Um dia desses até tinha um corren-
do atrás de uma leitoa minha, tive que passá um
susto no caboclo. Nós antigamente dormíamos
com as portas tudo abertas, hoje não se pode"
(Depoimento de um reconhecido guardião da
memória das principais famílias de Barreiro da
Boa Vista, município de Abadiânia, sobre o tu-
rismo e os pescadores que passaram a frequen-
tar a região por causa da barragem).
"Porque Corumbá IV é tudo isso e muito mais
do que isso. É energia. É água. É turismo. É
desenvolvimento. Mas é também um símbolo,
um ícone a indicar que é possível trilhar novo
caminho na busca do progresso" (Rogério Vilas
Boas, presidente da Companhia Energética de
Brasília - CEB, em artigo sobre a UHE Corum-
bá IV para o jornal Correio Brasiliense do dia
$27 / 2 / 2006$ ).

Fica evidenciado nas falas que há grandes divergências de perspectivas sobre um mesmo território em transformação. Em suma, verifica-se um cenário de diferentes atores em que se apresentam contrastes, interesses, valores e prioridades distintas. Esses vários níveis de interações, discursos, narrativas, poderes e negociações que constroem a nova ordem territorial no entorno da UHE compõem, na proposta deste artigo, um espectro semântico assimétrico. O poder de definir significado concreto 
para as definições abstratas das normas desfavorece os menos instrumentalizados politicamente nesse processo: posseiros, fazendeiros e trabalhadores rurais. Isso favorece uma nova ordem territorial que usurpa demandas dos desapropriados em prol da normatização estatal e da lógica empresarial para o território.

\section{Referências}

ASSIS, Luís Guilherme R. Às margens da UHE Corumbá IV, Goiás, Brasil: desafios antropológicos entre redes, enclaves, cosmografias e moralidades. 2007. 318f. Dissertação (Mestrado) - Programa de Pós-Graduação da UnB/ICS/DAN, Brasília, 2007.

BAINES, Stephen Grant. Usina hidrelétrica de Balbina e o deslocamento compulsório dos Waimiri-Atroari. Brasília: DAN/UnB, 1994. (Série Antropologia, 166).

BARRETO, Henyo. Da nação ao planeta através da natureza. Brasília: DAN/UnB, 1997. (Série Antropologia, 222).

BORGES, Barsanufo Gomides. Goiás nos quadros da economia nacional: 1930-1960. Goiânia: Editora UFG, 2000.

CARDOSO DE OLIVEIRA, Roberto; CARDOSO DE OLIVEIRA, Luís. Ensaios antropológicos sobre moral e ética. Rio de Janeiro: Tempo Brasileiro, 1996.

CATULLO, Maria Rosa. Poder e participación en Proyectos de Gran Escala - analysis comparativo de los procesos de relocalización por la construcción de la Represa Hidroelétrica Binacional Argentino-Uruguaya de Salto Grande. 1996. 266f. Tese (Doutorado) - Programa de Doutorado conjunto FLACSO/CEPPAC/UnB, Brasília, 1996.

DURKHEIM, Émile. Determinação do fato moral. In: Sociologia e filosofia. J.M. Toledo Camargo (tradutor). São Paulo, Rio de Janeiro: Editora Forense, 1970. p. 47-78.

FOLADORI, Guilhermo; TAKS, Javier. Um olhar antropológico sobre a questão ambiental. Mana, Rio de Janeiro, v. 10, n. 2, p. 323-348, out. 2004.

GLUCKMAN, Max. Análise de uma situação social na Zululândia Moderna. In: FELDMAN-BIANCO, Bela (Org.). Antropologia das sociedades contemporâneas: métodos. São Paulo: Global, 1987. p. 227-344.
LATOUR, Bruno. Reassembling the social. Oxford: Oxford University Press, 2005.

MEDEIROS, Rodrigo Augusto Lima de. Construção de significados no evento-situacional Usina Hidrelétrica Corumbá IV: desapropriações, reordenamentos e formação de uma ordem moral. 2007. 155f. Dissertação (Mestrado) - Programa de Pós-Graduação da UnB/ICS/ CEPPAC, Brasília, 2007.

RIBEIRO, Gustavo Lins. O capital da esperança: a experiência dos trabalhadores na construção de Brasília. Brasília: EdUnB, 2008.

SANTOS, Leinad Ayer de Oliveira; ANDRADE, Lucia Mendonça Morato de. Hidrelétricas do Xingu e os povos indígenas. São Paulo: Comissão Pro Índio São Paulo, 1988.

SUÁREZ, Mireya. Agregados, parceiros e posseiros: a transformação do campesinato no Centro-Oeste. Anuário Antropológico, Rio de Janeiro, n. 80, p. 13-60, 1982.

TURNER, Victor. Dramas, fields, and metaphors: symbolic action in human society. Ithaca: Cornell University Press, 1974.

VAINER, C. B. O plano de recuperação e desenvolvimento econômico e social das comunidades atingidas pelas barragens de Itá e Machadinho: uma experiência inovadora de extensão universitária e de planejamento. Cadernos IPPUR/UFRJ, Rio de Janeiro, ano 17, n. 1, p. 135-154, jan./jul. 2003.

VAINER, C. B. Grandes projetos e organização territorial: os avatares do planejamento regional. In: MARGULIS, Sérgio (Org.). Meio ambiente: aspectos técnicos e econômicos. Rio de Janeiro, Brasília: IPEA/ PNUD, 1990. p. 179-211.

VELHO, Gilberto. Projeto e metamorfose. Rio de Janeiro: J. Zahar, 1994.

VIANNA, Aurélio. Prisão em Lajeado Pepino: gênese e efeitos sociais de uma ação exemplar. Rio de Janeiro: Museu Nacional, 1996.

WOORTMANN, Klaas. Com parente não se neguceia. Anuário Antropológico, Rio de Janeiro, n. 87, p. 11-73, 1990. 


\section{Para publicar na revista}

Universitas Humanas,

acesse $o$ endereço eletrônico www.publicacoesacademicas.uniceub.br. Observe as normas de publicação, para facilitar e agilizar o trabalho de edição. 